\title{
Surgical Correction Is Ineffective for Improvement of Dyssynergic Defecation in Patients With Rectal Prolapse
}

\author{
Seon-Young Park, ${ }^{1}$ Sung-Bum Cho, ${ }^{1}$ Chang-Hwan Park, ${ }^{1}$ Jae-Kyun Joo, ${ }^{2}$ Young-Eun Joo, ${ }^{1}$ Hyun-Soo Kim, ${ }^{1}$ Sung-Kyu Choi ${ }^{1}$ and \\ Jong-Sun Rew ${ }^{1 *}$
}

Departments of ${ }^{1}$ Internal Medicine and ${ }^{2}$ General Surgery, Chonnam National University Medical School, Gwangju, Korea

\section{Background/Aims}

The patients with rectal prolapse suffer from not only a prolapse rectum but also associated dysfunction. However, most surgical techniques are successful regarding the prolapse, but either do not solve or even worsen defecation dysfunction. The purpose of this study was to investigate the functional and physiological results after surgical correction in patients with rectal prolapse.

\section{Methods}

This study is a retrospective review of a single-institution experience. Patients with rectal prolapse who underwent anorectal manometry before and after Delorme's procedure were included. The primary outcomes measured were improvement of clinical symptoms and physiologic study.

\section{Results}

Consecutive 19 patients with rectal prolapse (17 females, mean age of $68.1 \pm 10.8$ years) underwent anorectal manometry before and after Delorme's procedure. The two most prevalent symptoms before operation were rectal tenesmus (15/19, $78.9 \%)$ and excessive straining $(13 / 19,68.4 \%)$. The two most prevalent symptoms after operation were rectal tenesmus $(14 / 19,73.6 \%)$ and excessive straining $(13 / 19,68.4 \%)$. No significant differences in resting anal pressure, squeezing anal pressure, defecation index, and rectal sense were found postoperatively. However, vector asymmetry index before surgery was higher than that after surgery (35.0 vs. 32.0, $P=0.018)$. Ten patients $(52.5 \%)$ had type I dyssynergic defecation before surgery. No improvement of dyssynergic pattern occurred after surgery.

\section{Conclusions}

In conclusion, dyssynergic defecation was not improved after reduction of rectal prolapse in patients with rectal prolapse. Further study about combination treatment with biofeedback therapy in these subgroups may be necessary.

(J Neurogastroenterol Motil 2013;19:85-89)

Key Words

Defecation; Manometry; Rectal prolapse

Received: October 3, 2012 Revised: November 13, 2012 Accepted: November 21, 2012

(c) This is an Open Access article distributed under the terms of the Creative Commons Attribution Non-Commercial License (http://creativecommons. org/licenses/by-nc/3.0) which permits unrestricted non-commercial use, distribution, and reproduction in any medium, provided the original work is properly cited.

*Correspondence: Jong-Sun Rew, MD

Department of Internal Medicine, Chonnam National University Medical School, 42, Jebong-ro, Dong-gu, Gwangju 501-757, Korea Tel: +82-62-220-6296, Fax: +82-62-228-1330, E-mail: jsrew@jnu.ac.kr

Financial support: This Study was supported by a grant (CRI09072-1) of the Chonnam National University Hospital Research Institute of Clinical Medicine. Conflicts of interest: None.

Author contributions: Seon-Young Park: conception and design, analysis and interpretation, and drafting of the article. Jong-Sun Rew: conception and design, and final approval of the article. Sung-Bum Cho, Chang-Hwan Park, Jae-Kyun Joo, Young-Eun Joo, Hyun-Soo Kim and Sung-Kyu Choi: analysis and interpretation. 


\section{Introduction}

Complete or full-thickness rectal prolapse is the protrusion of the entire rectal wall through the anal canal; if the rectal wall has prolapsed but does not protrude through the anus, it is called an occult (internal) rectal prolapse or a rectal intussuception. ${ }^{1}$ The patients with rectal prolapse suffer from not only a prolapse rectum but also associated defecation dysfunction. More than $50 \%$ of the patients suffer from fecal incontinence. Fifteen to $65 \%$ of the patients have constipation, and excessive pushing during defecation induces injury of the mucosa of the rectal anterior wall, so the patient may also present with a solitary rectal ulcer. The etiology of this condition is still unknown; it may be possible to prolapsed rectum to block the passage of stool through the anal canal and to induce muscle dysfunction, spasm and hypertrophy of puborectalis muscles. ${ }^{2}$ And also, patients with rectal prolapse hesitate or avoid to exert adequate abdominal pushing force during defecation because it may get worse during defecation. So, we hypothesized that anatomical restoration of prolapsed rectum may lead to functional improvement of defecation. Numerous types of surgeries have still been introduced and attempted, both through the abdominal and perineal routes. Most surgical techniques are successful regarding the prolapse, but either do not solve or even worsen defecation dysfunction. ${ }^{3-5}$ The purpose of this study was to investigate the functional and physiological results after surgical correction in patients with rectal prolapse.

\section{Materials and Methods}

\section{Subjects}

A total of 19 patients with complete rectal prolapse undergoing anorectal manometry before and after Delorme's procedure were studied from July 2008 to August 2011. Abdominal and anorectal symptoms including obstructed defecation and fecal incontinence were evaluated using a structured questionnaire. The questionnaire about symptom was taken from all patients. The degree of patient self-assessed clinical symptom was assessed using a 4-point scale ( 0 , nil; 1 , mild; 2 , moderate; 3 , severe). The Institutional Review Board at Chonnam National University Hospital approved this study.

\section{Anorectal Manometry}

Anorectal manometry was performed before and 3 months after operation in all patients. Before anorectal manometry, patients were asked to empty their bowels. To measure resting and maximal anal sphincter pressure, a radial 8-channel anorectal water-perfused catheter was placed into the rectum at the level of 6 $\mathrm{cm}$ above the anal verge and automatically pulled by a catheter-pulling system at the rate of $1 \mathrm{~cm} / \mathrm{sec}$. The catheter was connected to a Mui 8-channel water perfusion system (Medtronics Inc., Minneapolis, MN, USA), and the anal sphincter pressure was measured 3 times. Next, a spiral 8-channel anorectal water-perfused catheter with a balloon was placed in the anal canal and both resting pressure and squeezing pressure were measured again. After the balloon on the tip of the catheter was gradually inflated by $10 \mathrm{~mL}$ of air, the recto-anal inhibitory reflex, the minimal volume for desire to defecate, the urgency volume, and the maximal tolerable volume were measured. POLYGRAM NET ${ }^{\circledR}$ software (Medtronic Inc., Minneapolis, MN, USA) was used to analyze anorectal manometry. Manometric results from all patients were reviewed and dyssynergic patterns were categorized as follows: type I dyssynergia, the subjects can generate an adequate propulsive force (rise in intrarectal pressure $\geq 40 \mathrm{mmHg}$ ) along with paradoxical increase in anal sphincter pressure; type II dyssynergia, the subjects is unable to generate an adequate propulsive force; additionally there is paradoxical anal contraction; type III dyssynergia, the subjects can generate an adequate propulsive force but there is either absent relaxation or incomplete $(\leq 20 \%)$ relaxation of anal sphincter; type IV dyssynergia, the subjects is unable to generate an adequate propulsive force together with an absent or incomplete relaxation of anal sphincter. ${ }^{3,6}$ To provide an overall index of the changes in the rectal and anal pressure during simulated defecation, we calculated a defecation index $=$ maximum rectal pressure when straining $\div$ minimal anal residual pressure when straining. ${ }^{7}$ The balloon expulsion test was conducted using a balloon catheter with spirally arranged eight channels. About $50 \mathrm{~mL}$ of warm water was placed in the balloon and the patient was requested to evacuate the balloon. ${ }^{8,9}$ Expulsion of the balloon within 5 minutes was defined as successful. Asymmetric patient was defined as a vector asymmetric index $>20 \%$, whereas in non-asymmetric patients, the vector asymmetric index was $<20 \%$.

\section{Delorme's Procedure}

The procedure was in all patients performed by the same surgical team, which was mainly devoted to colorectal surgery. Mechanical bowel preparation, preoperative prophylactic antibiotics, and deep venous thrombosis prophylaxis were used 
routinely. General, regional, and monitored anesthesia cares were all used. All patients were positioned in the prone jackknife position. Transanal suture of rectoanal mucosa was performed by using Eisenhammer's anal retractor.

\section{Statistical Methods}

The manometric data are expressed as median value (quartile). The categorical variables of each group were compared employing the Chi-square test or Fisher's exact test. The Wilcoxon signed-rank test was used to assess the effects of operation on each of the manometric parameters and clinical symptoms. A $P$-value $<0.05$ was regarded as statistically significant. All analyses were performed using SPSS version 19.0 for Window (SPSS Inc., Chicago, IL, USA).

\section{Results}

\section{Demographics}

The mean period of follow-up was 20.2 months (range 8.0-46.0 months). Nineteen patients (17 female and 2 male) with rectal prolapse were identified. The mean age of the study group was $68.1 \pm 10.8$ years. All patients had complete rectal prolapse. Twelve patients $(63.1 \%)$ had fecal incontinence before operation. The 2 most prevalent symptoms before operation were incomplete emptying $(15 / 19,78.9 \%)$ and excessive straining $(13 / 19,68.4 \%)$. The 2 most prevalent symptoms after operation were incomplete emptying $(14 / 19,73.6 \%)$ and excessive straining $(13 / 19,68.4 \%)$. Two patients $(2 / 19,10.5 \%)$ showed improvement of incomplete emptying after operation. Six patients $(6 / 19,31.5 \%)$ rather showed aggravation of incomplete emptying after operation. There was no significant improvement of clinical symptoms using 4-point scale between preoperative and postoperative period (Fig. 1). The overall recurrence rate was $21.0 \%$ (4 of 19). The mean time to recurrence was 17.8 months, with a broad range from 7 to 24 months.

\section{Balloon Expulsion Test}

Ten patients (52.6\%) were able to expel the balloon before surgery and 12 patients (63.2\%) were able to expel the balloon after operation. There was no significant improvement of ability to expel the balloon after surgery $(P=0.480)$ (Table).

\section{Anorectal Manometry}

Anorectal manometry data before and after surgery are listed in Table. Following surgery, the resting anal pressure and sus-

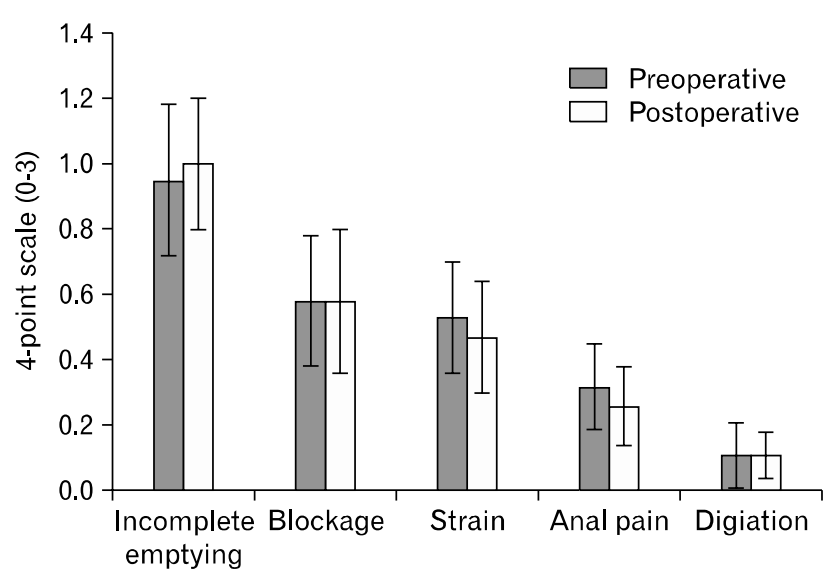

Figure 1. Comparison of preoperative and postoperative symptoms using a 4-point scale. There was no significant improvement of clinical symptoms using 4-point scale between preoperative and postoperative period (Wilcoxon signed-rank test).

tained squeezing pressure was not improved $(P>0.05)$. There was no significant difference between the preoperative and postoperative testing in the volumes for inducing a first sensation, desire to defecate, and urge to defecate. Rectoanal inhibitory reflex was normal in 11 patients, and indefinite in 6 patients due to low resting anal sphincter. No rectoanal inhibitory reflex changes occurred after surgery. Asymmetry index value in the preoperative group (median value, $35.0 \%$ ) was higher than that in the preoperative group (median value, $32.0 \%$; $P=0.018$ ) (Table).

\section{Dyssynergic Patterns}

Types of dyssynergic defecation are as follows; there were 11 patients $(57.8 \%)$ with type I dyssynergic defecation, 5 patients with type II, 1 patient with type III and 1 patient with type IV before surgery. Ten patients with paradoxical increase of anal sphincter before surgery still showed paradoxical increase of anal sphincter after surgery (Fig. 2). No improvement of dyssynergic pattern occurred after surgery.

\section{Rectal Sensation}

There was a decrease in the volume for urgency sensation after operation, but it was not statistically significant $(P>0.05)$ (Table).

\section{Discussion}

Surgical correction of rectal prolapse is the mainstay of therapy. Two approaches are commonly considered, transabdominal and transperineal. Transabdominal approaches have been 
A

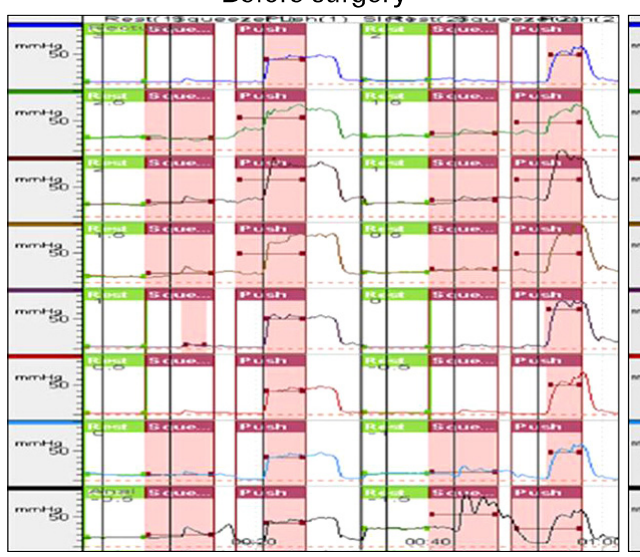

B After surgery

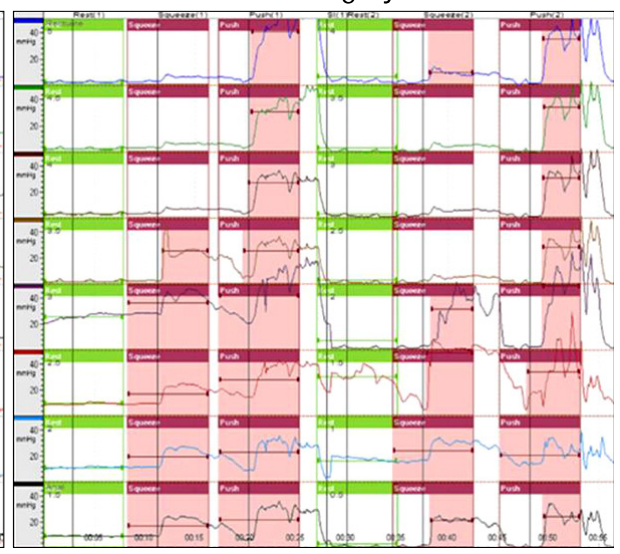

Figure 2. (A) Mannometric findings of a 70-year old woman show adequate propulsive force (rise in intrarectal pressure $\geq 40 \mathrm{mmHg}$ ) along with paradoxical increase in anal sphincter pressure; paradoxical increase. (B) Follow-up manometric features (after surgery) show still paradoxical increase in anal sphincter pressure.

Table. Results of Manometric Findings and Balloon Expulsion Test Before and After Operation

\begin{tabular}{lccc}
\hline & Preoperative (n=19) & Postoperative $(\mathrm{n}=19)$ & $P$-value \\
\hline Anal sphincter length (cm [median]) & $3.0(2.1-3.8)$ & $2.9(2.2-3.3)$ & 0.444 \\
Resting anal squeezing pressure (mmHg [median]) & $40.0(22.0-50.0)$ & $30.0(15.0-50.0)$ & 0.521 \\
Squeezing anal sphincter pressure (mmHg [median]) & $65.0(40.0-88.0)$ & $65.0(35.0-110.0)$ & 0.918 \\
Asymmetry values at rest (\% [median]) & $35.0(30.7-39.8)$ & $32.0(27.0-35.4)$ & 0.018 \\
Rectal sensation (mL [median]) & & & \\
$\quad$ Minimal volume for sense & $40(20-50)$ & $40(20-50)$ & 0.804 \\
$\quad$ Volume for desire to defecate & $80(50-100)$ & $80(50-90)$ & 0.141 \\
$\quad$ Volume for urgency sensation & $120(100-150)$ & $90(50-130)$ & 0.142 \\
Success rate of balloon expulsion test (n [\%]) & $10.0(52.6)$ & $12.0(63.2)$ & 0.480 \\
Defecation index (median) & $1.25(0.75-1.70)$ & $1.00(0.91-1.55)$ & 0.463 \\
\hline
\end{tabular}

associated with lower recurrence rates, but some patients with significant comorbidities are better served by a transperineal approach. Common transperineal approaches include a transanal proctectomy (Altmeier procedure), mucosal proctectomy (Delorme's procedure) or placement of a Tirsch wire encircling the anus. The goal of the transperineal approach is to remove the redundant rectosigmoid colon. ${ }^{10}$

Increased awareness of the functional abnormalities associated with rectal prolapse has resulted in the realization that appropriate surgery should not also be directed only at a reduction of the prolapse but also improve the functional abnormalities associated with rectal prolapse. ${ }^{11}$ Fecal incontinence occurs in about $70 \%$ case, ${ }^{12}$ difficulty with evacuation of the rectum in $50 \%{ }^{13}$ and constipation in up to $28 \% .{ }^{14}$ Difficulty in defecation and constipation can occur after abdominal rectopexy with a reported incidence ranging from $27-47 \%{ }^{6,15}$ However, most study report not extremely low constipation rate after Delorme's procedure, ranging between $0 \%$ and $16 \% .{ }^{16}$ Most previous studies did not show the improvement of physiologic study. Actually, in the present study, the proportion of patients who had sense of incomplete evacuation increased after surgery although the proportion of patients who had normal balloon expulsion test increased. And, physiologic study of anorectal manometry during attempted defecation did not show improvement of dyssynergic defecation and still showed paradoxical contraction of anal sphincter. In the present study, $62.9 \%$ of patients with paradoxical increase or inadequate relaxation of anal sphincter before surgery still showed dyssynergic defecation in the physiologic study. Among the patients, $26.3 \%$ showed inadequate pushing force during attempted defecation before and after surgery. These patients actually hesitated or avoided to exert adequate abdominal pushing force during defecation because they thought that increased abdominal pressure might get worse during defecation. However, they did not complain of defecation difficulty due to relatively lower anal sphincter pressure.

The most recent series of the Delorme's procedure report a 
variable recurrence rate of 5 to 22 percent. In our study, the result was disappointing with a $21.0 \%$ recurrence rate. Factors that may contribute to recurrence after a perineal repair include inadequate or incomplete mucosal dissection, failure to correct pelvic floor and outlet defects, a mucosa to mucosa only repair, and length of follow-up. ${ }^{17}$ In connection with difficulty in defecation and constipation, continuous straining may lead to further pelvic floor weakness from stretch injury to the pelvic floor and predispose to recurred prolapse. Therefore, the role of biofeedback after surgery needs to be investigated for improvement of dyssynergic defecation.

Evaluation of perioperative physiological changes remains to be established in patients with Delorme's procedure. Two previous studies, on the basis of manometric evaluation before and after Delorme's procedure, reported an improvement in rectal sensation. ${ }^{3,5}$ On the other hand, Türkün, did not show an improvement in rectal sensation after Delorme's procedure in accordance with ours.

Results regarding perioperative anal resting pressure and anal squeezing pressure are inconsistent cross series. ${ }^{4,5}$ In some studies, as in the present study, sphincter pressures remain unchanged, but parameters of sphincter pressure increase in other studies. ${ }^{3}$ The explanation for these differing results is not obvious. This may be related to variation in case mix and patient selection or because of a pudendal neuropathy or, to some degree, perirectal supra-elevator fibrosis following a subclinical anastomotic dehiscence, if any, with consequent impairment of rectal sensation. Furthermore, this may be because of the difference in the postoperative time of physiology study.

This study is limited by its retrospective nature and the limited number of subjects.

In conclusion, dyssynergic defecation was not improved after reduction of rectal prolapse in patients with rectal prolapse. Further study about combination treatment with biofeedback therapy in these subgroups may be necessary.

\section{References}

1. Felt-Bersma RJ, Cuesta MA. Rectal prolapse, rectal intussusception, rectocele, and solitary rectal ulcer syndrome. Gastroenterol Clin
North Am 2001;30:199-222.

2. Gutierrez C, Marco A, Nogales A, Tebar R. Total and segmental colonic transit time and anorectal manometry in children with chronic idiopathic constipation. J Pediatr Gastroenterol Nutr 2002;35:31-38.

3. Rao SS. Dyssynergic defecation and biofeedback therapy. Gastroenterol Clin North Am 2008;37:569-586. viii.

4. Cantore M, Fiorentini G, Luppi G, et al. Gemcitabine versus FLEC regimen given intra-arterially to patients with unresectable pancreatic cancer: a prospective, randomized phase III trial of the Italian Society for Integrated Locoregional Therapy in Oncology. J Chemother 2004;16:589-594.

5. Türkün LS. New trends in polishing direct resin composites. Pract Proced Aesthet Dent 2004;16:589-591.

6. Rao SS, Mudipalli RS, Stessman M, Zimmerman B. Investigation of the utility of colorectal function tests and Rome II criteria in dyssynergic defecation (Anismus). Neurogastroenterol Motil 2004;16: 589-596.

7. Huang YH, Zhang Y, Liang XM, Zhang MF. [Sex cord-like tumours exhibiting prominent Leydig cell differentiation: report of a case.] Zhonghua Bing Li Xue Za Zhi 2008;37:569-570. [Chinese]

8. Rao SS, Singh S. Clinical utility of colonic and anorectal manometry in chronic constipation. J Clin Gastroenterol 2010;44:597-609.

9. Scott SM, Gladman MA. Manometric, sensorimotor, and neurophysiologic evaluation of anorectal function. Gastroenterol Clin North Am 2008;37:511-538. vii.

10. Felt-Bersma RJ, Tiersma ES, Cuesta MA. Rectal prolapse, rectal intussusception, rectocele, solitary rectal ulcer syndrome, and enterocele. Gastroenterol Clin North Am 2008;37:645-668. ix.

11. Elgadaa AH, Hamrah N, Alashry Y. Complete rectal prolapse in adults: clinical and functional results of Delorme procedure combined with postanal repair. Indian J Surg 2010;72:443-447.

12. Yoshioka K, Hyland G, Keighley MR. Anorectal function after abdominal rectopexy: parameters of predictive value in identifying return of continence. Br J Surg 1989;76:64-68.

13. Brodén G, Dolk A, Holmstrom B. Evacuation difficulties and other characteristics of rectal function associated with procidentia and the Ripstein operation. Dis Colon Rectum 1988;31:283-286.

14. Sayfan J, Pinho M, Alexander-Williams J, Keighley MR. Sutured posterior abdominal rectopexy with sigmoidectomy compared with Marlex rectopexy for rectal prolapse. Br J Surg 1990;77:143-145.

15. Farfal S, Marchelek M, Dutkiewicz G, Rózański J, Ciechanowski K, Maleszka R. [Tuberous sclerosis - symptoms, diagnosis and treatment.] Pol Merkur Lekarski 2004;16:589-591. [Polish]

16. Bäckberg M, Ultenius C, Fritschy JM, Meister B. Cellular localization of GABA receptor alpha subunit immunoreactivity in the rat hypothalamus: relationship with neurones containing orexigenic or anorexigenic peptides. J Neuroendocrinol 2004;16:589-604.

17. Watkins BP, Landercasper J, Belzer GE, et al. Long-term follow-up of the modified Delorme procedure for rectal prolapse. Arch Surg 2003;138:498-502; discussion 502-503. 